\title{
BEHAVIOURAL ECONOMICS AND ITS IMPLICATIONS ON REGULATORY LAW
}

\author{
Jana Bellová ${ }^{1}$
}

\section{Faculty of Law, Palacký University Olomouc, Czech Republic email: jana.bellova@upol.cz}

BELLOVÁ, Jana. Behavioural Economics and its Implications on Regulatory Law. International and Comparative Law Review, 2015, vol. 15, no. 2, pp. 89-102. DOI: 10.1515/iclr-2016-0037.

\begin{abstract}
The aim of this article is to analyse the possible implications of behavioural economics on regulatory law and government policy. In order to do so it first introduces and in short describe the current trends in behavioural economics through a quick look into the aim and history of this relatively new and innovative field of economics. The article then analyses the combination of this field of study with law in the form of a rather specific field of study called behavioural law and economics. The analyses of the possible impact on government policies and the regulation in certain areas then follow and result in suggestions of further possible interactions between law and economics.
\end{abstract}

Keywords: Behavioural economics (BE), agents, behavioural law and economics (BLE), government policy, regulations

\section{Introduction}

In context with the aim of the article which is to analyse the impact of behavioural economics on regulatory law and government policies, the article is divided into several interconnected sections first of which is behavioural economics as an actual field of study. As a follow up of the findings it then seems necessary to provide further attention to the aspect of rationality, which is one of the core aspects of neoclassical main stream economics and as BE is based on the criticism of this assumption it seems necessary to give space to rationality, difference between rationality and being rational, and introduces the core aspect of Behavioural economics ${ }^{2}$ which is the bounded rationality concept. Once the above mentioned aspects have been introduced the article then analyses the impact on law and policies today and leads to the analysis of concepts of Behavioural law and economics ${ }^{3}$. It also discusses its negative effects which are mainly focused

1 Ing. Jana Bellová, Ph.D., Palacký University Olomouc, Faculty of Law, Department of Politics and Social Science, Czech Republic, email: jana.bellova@upol.cz.

2 Further on abbreviated as BE.

3 Further on abbreviated as BLE. 
on the idea of so called soft paternalism which seems to be the answer given by BLE. Consequently this provides a lot of room for regulatory law and government policy in order to guide agents to their most satisfactory choice but on the other hand interfere with the concept of the individuals' or the agents' free will as well as the ability to pursue what they believe is best for them. Hence quite controversial reception of such findings may often be expected.

\section{Behavioural economics ${ }^{4}$}

As the name indicates, behavioural economics is a so called hybrid area of research that incorporates principles, concepts and ideas mainly from psychology but also from other social sciences like sociology, philosophy or politics into economic theory. ${ }^{5}$

Simply put when referring to behavioural economics it is understood to have in mind the amalgamation of economics with psychology, but it could include the combination of economics with any other social science.

But is there a necessity to combine these different fields? And if so, for what purposes? It all comes from the idea of a so called rational agent. What is the rational agent? From the very birth of economics as a discipline and the conceptualisation of Adam Smith one of the key elements is the presumption that a man is rational and would try to maximise his resources.

Yet many challenges posed to mainstream economics have inspired contemporary behavioural economists to develop alternative models of choice that better explain why and in what contexts individuals might select courses of action or consumption alternatives, which are regarded as biased or even irrational. ${ }^{6}$

One of the major problems of the so called main stream economics is the fact that it is based on the presumption of the rational agent. But unfortunately in real life there are many examples which seem to indicate that agents are irrational, that very often agents or in other words humans make decisions which appear at face value to contradict the principle that agents act in a rational way.

Behavioural economics tries to explain and ultimately to apply these findings into practice, that is why individuals frequently make irrational decisions and choices, and why and how their behaviour does not match the patterns predicted by neoclassical models. ${ }^{7}$

4 Further on abbreviated as BE.

5 DIACON, P., DONICI, G., MAHA, L. Perspectives of economics - behavioural economics. Theoretical and Applied Economics. Vol. 20, no. 7, p. 29, 2013.

6 MURAMATSU, R., FONSECA, P. Freedom of choice and bounded rationality: a brief appraisal of behavioural economists 'plea for light paternalism. Brazilian Journal of Political Economy. Vol.32, no. 3, p. 446, 2012.

7 DIACON, P., DONICI, G., MAHA, L. Perspectives of economics - behavioural economics. Theoretical and Applied Economics. Vol. 20, no. 7, p. 29, 2013. 
Behavioural economists replace the assumption of rationality with one of so called bounded rationality, in which consumers ' actions are affected by their initial endowments, their tastes for fairness, their inability to appreciate future costs, their lack of self-control, and the general use of flawed heuristics. ${ }^{8}$

Behavioural economists try to make sense of the agent's actions and take into account all these variables in order to predict various outcomes and impacts on the economy.

So where does Behavioural economics have its roots? In some respects it's not as new as some might think and the birth of this academic discipline can be traced back to the mid twentieth century. It is the Michigan Institute of Social Research that has been credited as the place this discipline first took off.

Then the use of behavioural economics was initially popularized at the University of Michigan's Institute of Social Research in the late 1940s, where George Katona understood behavioural economics as investigating economic behaviour. ${ }^{9}$

Though others have stated that the studies of Allias and Elsberg were the first in the field of behavioural economics. That takes us back to the years 1953 when Allais and 1961 when Elsberg came out with publications concerning the paradox of the rational choices on the notion of unclear decision theory. Yet it is only relatively recently that behavioural economics has really established itself as an alternative theory to the standard theory based on the criticism of the latter.

With the academic battle over the relative virtue of market versus governmental allocation of resources largely settled by the 1950s, economists devolved their efforts to extending the so called neoclassical frameworks to explain realworld phenomena observed in the markets. ${ }^{10}$

Basically as stated above $\mathrm{BE}$ was developed as a reaction to the inadequacies of the neoclassical model which is rather an important building stone of main stream economics. But what exactly is the neo - classical model? What does it assume? Why should it be criticized?

Wikipedia ${ }^{11}$ defines it as a branch of economics that studies the allocation of scarce resources between competing uses and users, based on principles of market equilibrium and profit maximization.

8 COOPER, J. C.,KOVACIC, W.E. Behavioral economics: implications for regulatory behaviour. Journal of Regulatory economics. Vol.41., p. 42, 2012.

9 HEUKELOM, F. Behavioral economics. Camebridge University press. p.4.2014. ISBN 9781-107-03934-6

10 WRIGHT, J., D., Ginsburg, D.,H. Behavioral Law and Economics: Its origins, fatal flaws and implications for liberty. Northwestern university Law review. Vol.106, no 3, p. 1037, 2012.

11 http://en.wikipedia.org/wiki/Neoclassical_economics 
According to the neoclassical model then, people and companies are always assessing the value of the things that they do and try to maximize the profit they get from it. But some researchers have questioned if this is actually the case that people are only interested in furthering their own economic wealth.

The studies of Rabin contradict the assumption that people work only in their own interest, not caring about what he calls social goals. In his paper he presented a model that accounts for the so called element of integrity, that is, the readiness of people to sacrifice their own materialistic well-being to help someone who is kind or punish one who is not, although the model does suggest that behaviour implications are greatest when the material consequences are not too significant. ${ }^{12}$

So perhaps we are not as egocentric as the neoclassical model would have us believe and there are other more complex reasons for our behaviour than the maximization of our own utilities. Rabin was not the only researcher to discover other motivations behind an individual's behaviour other than the maximisation of their resources.

The studies of Fehr and Schmidt confirm that there is a fraction of people who are also motivated by fairness considerations and that the classical theory of the homo oeconomicus with purely egotistical motives is not observed in real life. ${ }^{13}$

Thus the above mentioned studies question the fundamental basis of the neoclassical model which logically led some to explain the other possible motivations of people and why they act the way that they do in a certain situation. This eventually led to the birth of a new field of research, behavioural economics.

Behavioural economics offers more realistic explanations of human decisions and macroeconomic processes than the neoclassical approach. It is rapidly invading other areas of life such as psychology and entering the economic realm. ${ }^{14}$

As briefly stated the $\mathrm{BE}$ is a mix of economics, psychology and the social sciences. But what makes BE separate from Psychology and other social sciences?

Behavioural economists came to define themselves across sub-disciplinary lines in the 1990s and 2000s. First, behavioural economics became defined as economics on the basis of its use of mathematical modelling. This use of math-

12 BRZEZICKA, J., WISNIEWSKI, R. Homo Oeconomicus and Behavioral Economics. Contemporary Economics Vol.8, Issue 4, 2014, p. 358.

13 Ibid.

14 BRZEZICKA, J., WISNIEWSKI, R. Homo Oeconomicus and Behavioral Economics. Contemporary Economics Vol.8, Issue 4, 2014, p. 361. 
ematics was something that defined behavioural economics as economics, and therefore as different from psychology. ${ }^{15}$

The core of current behavioural economics is Kahneman and Tversky's prospect theory. They state that in creating the theory they deliberately proceed as conservatively as possible. Kahneman and Tversky created a combination of neoclassical economics and cognitive psychology, and their approach has remained the approach of all researchers in the field. ${ }^{16}$

The prospect theory departs from the neoclassical model in that it argues that people weigh the potential losses and gains rather than the final outcome. There has been a fair amount of research in this particular area and the article will look into later.

\section{Bounded rationality}

As already outlined a key element of neoclassical economics is the idea of a rational agent acting rationally to maximise his own economic gains. But how is rationality defined?

Rationality is defined as acting so as to maximize subjective expected value, and the implicit assertion is that persons should act so as to maximize their selfinterest over the time horizon they can encompass. Not doing so is defined as

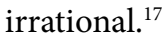

But is someone acting altruistically irrational? It seems to be a sad state of affairs that helping someone in trouble and expecting no gain from it is considered irrational.

Economic rationality can be characterized by self-interested goals or not. Behaving altruistically is not always equivalent to behaving irrationally. ${ }^{18}$

So the concept of rationality itself is not stable as it is evolving with contemporary theories.

Thus, it will be proved that the words rational and rationality do not possess the same meaning. ${ }^{19}$

Reality is different because many risk their safety to get instant gratification. However, in the acceptation of von Mises the individual is rational because it acts in order to satisfy their needs. ${ }^{20}$

15 HEUKELOM, F. Behavioral economics. Camebridge University press. p.191.2014. ISBN 978-1-107-03934-6

16 JEFFREY, H.,.,., PUTMAN, A., O. The Irrationality Illusion: A New Paradigm for Economics and Behavioral Economics. The Journal of Behavioral finance. Vol.14, p.162, 2013.

17 Ibid.

18 ZOUBOULAKIS, M. The varieties of economic rationality. Routledge, p.2, 2014.

19 Ibid.

20 MAHA, L., DIACON, P., DONICI, G. Liberalisation and regulation in the financial crisis - is behavioural economics a solution? Theoretical and Applied Economics. Vol. 20, no. 3, 
As economists began to observe situations where people seemed to be acting differently they began to ask themselves why. What are the reasons behind such behaviour? Is it irrational? This led to the concept of bounded rationality.

Bounded rationality is the idea proposed by Herbert Simion became one of the pylons on which behavioural economies is set. This idea advocates that rationality of people is a priori limited by given factors like access to information, their finite amount of time, and the cognitive limitations of their mind. ${ }^{21}$

Economists began to make allowances and to understand that man was not perfect and there were internal and external influences which affected his behaviour.

March and Simon are the first to have questioned the assumption of absolute rationality by introducing the concept of bounded rationality. They indicate that the rationality of an agent is limited by three factors and consequently, they substitute the goal of maximizing the expected utility by that of satisfaction meaning that the individual does not take an optimal decision but rather a satisfactory decision. The three key factors of bounded rationality are: ${ }^{22}$

1. the assumption that the information is incomplete

2. the assumption of what they refer to as individual motivations

3. the assumption that the actors' capacities are limited

So the agent is determined to seek satisfaction for his wants rather than using his resources to their maximum effect. Sometimes his satisfaction may be short sighted or short lived.

Main stream economics assumes that people are rational, patient, forward thinking, and proficient at decision making, thereby making choices that maximize their utility by which they mean the benefits a person derives from a good or service. However, we know that individuals often have difficulty making wise choices, especially when faced with decisions that involve uncertainty, trade-offs between current and future costs and benefits, or significant complexity. ${ }^{23}$

BE examines the implications for decision-making of agents when actors suffer from biases documented in the psychological literature. BE scholars replace the assumption of rationality by bounded rationality in which the agents' actions are affected by their initial endowments, their tastes for fairness, their inability

p.150, 2013.

21 DIACON, P., DONICI, G., MAHA, L. Perspectives of economics - behavioural economics. Theoretical and Applied Economics. Vol. 20, no. 7. p. 30. 2013.

22 JARBOUI, S., BOUJELBENE, Y. The behavioral Approach and the rationality of Economic Decisions: Application to Banks Managers. Global business and management research: An International Journal. Vol. 4, no. 2, p. 208, 2012.

23 RIEDEL, J., COLAO, R. Change is hard: The promise of behavioral economics. American Journal of Health Promotion.Vol.28. no. 6, p. TAHP8, 2014. 
to appreciate future costs, their lack of self-control, and the general use of flawed heuristics. ${ }^{24}$

From the perspective of BE we can accept the idea of a rational individual if we reformulate it and accept that the homo oeconomicus of neoclassical taught, when seeking to maximize utility, does not seek to achieve the highest possible monetary compensation at the end of the day, but the highest satisfaction possible. $^{25}$

\section{The impact of behavioural economics on policy today}

The emerging field of BE seeks to develop more precise theory on the behaviour of economic agents. The recent success of this new approach shows the gap between economic theory and reality can take time to fill. ${ }^{26}$

As stated in previous chapters over time the neoclassical view of the world has become less attractive as it seems to fail to explain certain situations or events. Economists have begun to appreciate that people are less predictable or do not act in the way the model suggests.

Standard economic models exclude emotions because they are too complex, unruly and ephemeral. But today, the behavioural economists add a psychology dimension to the traditional economic model to take account of emotions and human irrationality. ${ }^{27}$

The economic events will never be really understood unless confronted with the fact that their causes are largely mental in nature. This assumption stands in opposition to the neoclassical approach, which postulates that human beings are unrestrained in their optimal decisions, self-control, plans, intentions, ability to overcome problems, internal barriers and profit calculations. ${ }^{28}$

At the core of behavioural economics is the conviction that increasing the realism of the psychology underlying economic analysis will improve the field of economics on its own terms-generating theoretical insights, making better predictions of field phenomena, and suggesting better policy. ${ }^{29}$

24 COOPER, J. C.,KOVACIC, W.E. Behavioral economics: implications for regulatory behaviour. Journal of Regulatory Economics. Vol.41, p. 42, 2012.

25 MAHA, L., DIACON, P., DONICI, G. Liberalisation and regulation in the financial crisis - is behavioural economics a solution? Theoretical and Applied Economics. Vol. 20, no. 3, p. 150, 2013.

26 JARBOUI, S., BOUJELBENE, Y. The behavioral Approach and the rationality of Economic Decisions: Application to Banks Managers. Global business and management research: An International Journal. Vol. 4, no. 2, p. 205, 2012.

27 Ibid.

28 BRZEZICKA, J., WISNIEWSKIU, R. Homo Oeconomicus and Behavioral Economics. Contemporary Economics.Vol.8, Issue 4, 2014, p. 355.

29 DOW, S.,C.,Formalism, rationality, and evidence: the case of behavioural economics. Erasmus Journal for Philosophy and Economics. Vol.6/3, 2013, p.31. 
So it would appear that BE may be able to give us useful insights into the human mind which may help guide policy makers in making better decisions, or at least more economically efficient decisions.

The financial crisis has provided new impetus to behavioural economics, in the search for an explanation for events which would seem to constitute massive falsifying evidence to a body of theory which presumed markets to be efficient and equilibrating. ${ }^{30}$

So the mainstream view of the economy seemed at the very least to be suspect, and obviously politicians also need to convince the electorate that they are in control and that lessons have been learnt and that there is an alternative to avoid such a situation in the future, i.e. BE.

Among others, BE became an important source of inspiration for a number of advisors and bureaucrats in the new Obama administration that came into power in January 2009. ${ }^{31}$

The Obama administration is not the only one to call in behavioural economists to help in policy making decisions. The British Prime Minister David Cameron has also set up his own group of advisors which include behavioural economists.

Although BE may seem to many to be able to answer the failings of neoclassical assumptions it is not without fault.

There has been a range of critiques of $\mathrm{BE}$ on the grounds that it can provide ex post explanations for behaviour, but falls short on prediction. ${ }^{32}$

The usefulness of a theory or model that can tell us why something has happened after it has happened is arguably limited. Yes it is nice to know why something happened but stopping it from happening again or predicting and taking preventative action is surely more important. One strength of $\mathrm{BE}$ is that its findings are and can be proved in experiments where conditions are controlled and monitored, but this can also be seen as a weakness.

Many behavioural economic studies were conducted as experiments under lab conditions. This method is preferred by scientists because it allows extraneous variables to be controlled. However, extensive reliance on lab studies has led some critics to suggest that behavioural economics' key findings may apply only

30 DOW, S.,C.,Formalism, rationality, and evidence: the case of behavioural economics. Erasmus Journal for Philosophy and Economics. Vol.6/3.2013, p. 27.

31 HEUKELOM, F. Behavioral economics. Camebridge University press. p.191.2014. ISBN 978-1-107-03934-6

32 DOW, S.,C.,Formalism, rationality, and evidence: the case of behavioural economics. Erasmus Journal for Philosophy and Economics. vol 6/3, 2013, p. 35. 
- or at least much more strongly - under the artificial conditions of the lab, and not in the field. ${ }^{33}$

One other significant fault is like the neoclassical model it fails to explain some occurrences.

We know, for example, that various political, psychological, and social factors lead to certain actors engaging in the behaviour of suicide bombing, which cannot be justified by any form of the neoclassical model but which also cannot be explained or predicted by any existing model provided by BE, unless the concept of subjective utility is arbitrarily expanded. ${ }^{34}$

This is a problem for $\mathrm{BE}$ as it cannot answer some of the problems that the neoclassical model could not answer either and as a consequence perhaps it is reliant on a model which is already flawed and thus will always be left wanting.

Behavioural economics, as the field stands today, consists of standard neoclassical economics with several psychological factors grafted on to account for some, though by no means all, of the failures of the neoclassical model. The result is an ad hoc collection of concepts and factors that are basically disconnected, standalone concepts. ${ }^{35}$

There are also other problems with BE. It may be caused by its relatively new prominence or the fact that it is based on a flawed model but there are some new concepts which are contradictory or at the very least the relationship between the elements is unclear.

The key thesis of BE being the systematic biases that are built into people's choices which prevent utility maximization is subject to different interpretations. One can hold that these systematic limitations are found in all people, are congenital or even wired in a universalistic interpretation, or that they are found only among some people or that one and the same person can sometimes optimize and at other times cannot. BE would benefit if this important issue would be clarified. ${ }^{36}$

\section{Introduction of Behavioural Law and Economics ${ }^{37}$}

With the emergence of BE it was only a matter of time before law would be combined with it in some way as the two fields are inter related.

33 ETZIONI, A. Behavioural Economics: Next steps. Journal of Consumer policy. Vol. 34, 2011, p. 287.

34 JEFFREY, H.,J., PUTMAN, A., O. The Irrationality Illusion: A New Paradigm for Economics and Behavioral Economics. The Journal of Behavioral Finance. Vol.14, p.162, 2013.

35 Ibid.

36 ETZIONI, A. Behavioural Economics: Next steps. Journal of Consumer policy. Vol. 34, 2011, p. 280.

37 Further on abbreviated as BLE. 
It should be observed that comparative law scholars are in effect already capitalizing on research in behavioural economics by using this research's insights on how people actually behave - as opposed to mere hypothesized behaviour - as a basis for evaluating the effectiveness or efficiency of supranational rules and doctrines. $^{38}$

It seems natural that learning about an agents economic behaviour might have some useful spin offs, especially in the regulation of the financial industry as a result of the financial crisis for example.

Emerging close on the heels of behavioural economics over the past thirty years has been the BLE movement, which explores the legal and policy implications of cognitive biases. ${ }^{39}$

As has been mentioned before the Obama administration has been quick to see the advantages of BE and consequently of BLE.

Regulatory policies in the United States are already being informed by BLE. President Obama issued an Executive Order requiring federal agencies to consider regulatory options that preserve what is referred to as freedom of choice for the public, and is now forming a so called Behavioural Insights Team to employ BLE work more broadly and systematically across the government. ${ }^{40}$

The promise of BLE is to regulate so as to improve economic welfare by more closely aligning each individual's actual choices with his true or unbiased preferences without reducing his liberty, at least as it is represented by the choices available to him. ${ }^{41}$

BLE rather seeks to identify systematic departures from rational decisionmaking by empirical research and make policy recommendations based on these insights. ${ }^{42}$

The argument is that people have a desire to do something but are stopped from doing so by some inbuilt biases which can be unveiled by BLE research. Even if an agent can understand that a certain course of action is not good for them they still continue with the action at their own detriment. Thus the idea

38 DeCONINCK, J., Reinvigorating Comparative Law through Behavioral Economics? A Causiously Optimistic View. Review of Law and Economics, Vol.7, no 3, 2011, p.712.

39 WRIGHT, J., D., GINSBURG, D.,H. Behavioral Law and Economics: Its origins, fatal flaws and implications for liberty. Northwestern university Law review. Vol.106, no 3, p. 1034. 2012.ISSN 0029-3571

40 BUBB, R., PILDES, R.H. How behavioural economics trims its sails and why. Harward Law review.Vol. 127:1593.2014.p. 1596.2014. ISSN 0017-811X

41 WRIGHT, J., D., GINSBURG, D.,H. Behavioral Law and Economics: Its origins, fatal flaws and implications for liberty. Northwestern university Law review. Vol.106, no 3, p. 1035, 2012.

42 PURNHAGEN, K. The behavioural law and economics of the precautionary principle in the EU and Its Impact on Internal Market Regulation.Journal of Consumer policy. Vol. 37, p. $458,2014$. 
of paternalistic regulation has begun to evolve. If the policy makers discover a certain weakness in their agents then it may be considered only fair and just to help those agents avoid making such mistakes.

Behavioural findings showing the failure of individual choice often point toward policy prescriptions that limit choice or mandate outcomes. But most proponents of BLE do not push analysis to this point and focus instead on lighttouch regulatory tools that preserve wide scope for choice. ${ }^{43}$

In a nutshell, psychological economist's goal is to use behavioural conceptual tools to overcome individual cognitive limitations and/or emotional and affective dispositions that sometimes lead to distorted and even self-destructive patterns of behaviour. ${ }^{44}$

\section{Analysis of selected findings}

We are loss averse. Loss aversion refers to the tendency for people to prefer avoiding losses to acquiring gains. Studies suggest that losses are as much as twice as psychologically powerful as gains. Tversky and Kahnemann. They showed that people are generally risk averse when facing gains but risk seeking when facing losses. For instance, a penalty is a stronger incentive than a similarsized reward. ${ }^{45}$

This could obviously have a big impact on BLE as it suggests that a policy where people are fined would be more effective than one where you are offered a reward. For instance if the policy wanted to encourage people to hand in their tax forms in on time a penalty for those handing the form late would be more effective than a reward to those handing it in on time. Other studies have also found that other people's actions may impact on our own.

We are influenced by social forces. Individuals informed about the actions of others tend to conform to others behaviours. ${ }^{46}$

Also giving people too many choices may be a bad thing as they have too much information and fall back into the default position of doing nothing. An example of such behaviour is the case of optional healthcare insurance providing that the competitiveness in the market with personal healthcare insurance is not anyhow limited and hence in accordance with the idea of free market. In that case a large amount of people may fail to get insured simply because of the complexity and amount of choice. This could generally apply to the whole idea of the

43 BUBB, R., PILDES, R.H. How behavioural economics trims its sails and why. Harward Law review Vol. 127:1593, p. 1596, 2014.

44 MURAMATSU, R., FONSECA, P. Freedom of choice and bounded rationality: a brief appraisal of behavioural economists' plea for light paternalism. Brazilian Journal of Political Economy. Vol.32, no.3, p. 449. 2012.

45 RIEDEL, J., COLAO, R. Change is hard: The promise of behavioral economics. American Journal of Health Promotion. Vol.28, no. 6, p. TAHP8, 2014.

46 Ibid. 
free market that assumes that the agents have at their disposal all the available information which for quite obvious reasons is only a theoretical assumption. It not only fails to copy the reality but quite frankly it could be argued that it may not even be the most desired situation for the agents themselves and their decision making process. The fact that it may not be in their interest to get as much information as possible in order to make the desired decision because that could lead to the opposite effect; that is, not actually acting at all due to too much information. This tends to shake the findings on which economics is based.

Also called choice overload, as the number of choices expands people become overwhelmed and choose nothing, or select the default option. ${ }^{47}$

These findings support public policies that are built on so called liberal choice architecture suggested by Thaler and Sunstein in 2008 which entails making organizational arrangements that help people make better choices, without requiring them to process information or learn to control their loss aversion or other emotions. ${ }^{48}$

One of the impacts of BE and BLE reality is the argument that you can and should try to guide agents to the optimal decision helping them maximise their satisfaction as they are not capable of doing so themselves. Which again gives space and the impulse for government policies?

Soft paternalistic interventions are justified in terms of the view that the person towards whom we act paternalistically is not competent due to ignorance, irrational propensities, deficiencies in cognition and emotional dispositions. ${ }^{49}$

It has been observed that small changes in wording or context can change agents' actions. Thus small changes in laws and regulation which take into account these factors may be beneficial for the agent.

Behavioural economists offer compelling evidence that boundedly rational agents' choices are influenced by small changes in context, default rules, legal and organizational rules and sensitive to framing effects and inertia. If this is so, we can conclude that boundedly rational individuals sometimes fail to make choices that are in their best interests. This gives room for attempts to overcome suboptimal behaviour by means of paternalistic measures. ${ }^{50}$

But there is still the position maintained by rather few that any interference with an agents will is unacceptable even if it is in the agents best interest. The

47 Ibid.

48 ETZIONI, A. Behavioural Economics: Next steps. Journal of Consumer policy. Vol. 34, 2011, p. 282.

49 MURAMATSU, R., FONSECA, P. Freedom of choice and bounded rationality: a brief appraisal of behavioural economists' plea for light paternalism. Brazilian Journal of Political Economy. Vol.32, no.3. p.449. 2012. ISSN 0101-3157

50 MURAMATSU, R., FONSECA, P. Freedom of Choice and Bounded Rationality: a brief appraisal of behavioural economists' plea for light paternalism. Brazilian Journal of Political Economy. Vol.32, no.3, p.448, 2012. 
supposition is that if the state interferes though for the good of the agent, is it then the state who should determine what is good for the agent or when to act in the agents' interest? These are just some of the problems which the paternalism debate brings up.

BLE often artificially and wrongly excludes more traditional regulatory tools, such as direct mandates, from its analysis of policy options. BLE sometimes fails to properly evaluate how its own regulatory tools actually function or ways in which actual individual behaviour suggests those tools should be modified or abandoned. ${ }^{51}$

Another criticism of BLE is that it does not properly evaluate the effect of its own regulatory tools and as mentioned in the previous paragraphs what is considered soft paternalism might in effect turn out to be something far stronger.

Behavioural insights themselves powerfully suggest that people stay with the status quo for all the reasons so central to BLE in the first place: people are inertial, passive, or under the impression that the default must represent the right choice, whether it does or not. As a result, these defaults function in practice, for many individuals, as effective mandates. ${ }^{52}$

Also if you accept that the state knows better than the agent is it not also suggesting that no one is allowed to make mistakes, must we always make the right decision? What is so wrong about making mistakes? Do we not learn from our failures?

Wright and others ${ }^{53}$ argue that so long as libertarian paternalism ignores the economic welfare and liberty value of allowing individuals the freedoms to err, it will fail to achieve its goals of increasing welfare without reducing liberty and will pose a significant risk of reducing both.

\section{Conclusion}

It can be claimed of many new theories that they did not live up to expectations but perhaps sometimes expectations are too high and too demanding. BE does not have all the answers to the neoclassical failures but given time it may provide useful insights into different areas of economic and legal life. After all BE is a relatively new field and it may take a while to establish itself and to iron out the wrinkles left by the neoclassical model.

51 BUBB, R., PILDES, R.H. How behavioural economics trims its sails and why. Harward law review.Vol. 127:1593.2014, p. 1597.

52 Ibid

53 WRIGHT, J., D., GINSBURG, D.,H. Behavioral Law and Economics: Its origins, fatal flaws and implications for liberty. Northwestern university law review. Vol.106, no 3, p. 10331088, 2012. 
Behavioural economics is not a miracle solution that has the ability to replace Keynesian or liberalism, but its use can improve the theories and models of both schools of thought. ${ }^{54}$

$\mathrm{BE}$ has aimed at providing a more scientific basis for its theories which it tries to conduct in laboratory situations to give its theories a solid base which in itself is an achievement.

Given that many other social science findings have not been replicated either because no one has tried them or they did not pan out, behavioural economists deserve high marks in this regard. ${ }^{55}$

It can clearly be seen that BE and BLE are considered to be the new and in fields of research attracting the majority of researchers attention. It is perhaps no wonder when you consider the inputs of Kahneman and Tversky who found that agents were loss adverse and risk seeking and all the associated implications for government policy this may have.

Predictably Irrational and Nudge thus elucidate the systematic and pervasive nature of irrationality and can inform policy in every legal field, ranging from consumer protection and environmental protection, through employment and health policies, to tax and financial regulation..$^{56}$

The implications of BE and BLE are wide and varied as with the case of soft paternalism it may sometimes be for the good and sometimes it may lead to further problems. But one thing is sure and that is it is currently influencing government policy around the world.

More recently, it suggests that, in a real world of boundedly rational agents, economics could help to improve the quality of their choices without any harm to autonomy and freedom of choice. ${ }^{57}$

By understanding the ways in which individuals are susceptible to biases and flawed decision-making, law and policy can help improve individual and group behaviour. ${ }^{58}$

The question though is how much will this soft paternalism penetrate into our lives and will we be able to make mistakes in the future? Only time will tell.

54 MAHA, L., DIACON, P., DONICI, G. Liberalisation and Regulation in the Financial crisis - is behavioural economics a solution? Theoretical and Applied Economics. Vol. 20, no. 3, p.151, 2013.

55 ETZIONI, A. Behavoural Economics: Next steps. Journal of Consumer policy. Vol. 34, 2011, p. 278.

56 AMIR, O., LOBEL, O. Stumble, predict, nudge: How behavioural economics informs law and policy. Columbia Law review. Vol.108:2098. p. 2099, 2008.

57 MURAMATSU, R., FONSECA, P. Freedom of choice and bounded rationality: a brief appraisal of behavioural economists' plea for light paternalism. Brazilian Journal of Political Economy. Vol.32, no.3, p. 445. 2012.

58 AMIR, O., LOBEL, O. Stumble, predict, nudge: How behavioural economics informs law and policy. Columbia Law Review. Vol.108:2098, p. 2099, 2008. 